\title{
Dietético y dietario ${ }^{\dagger}$
}

\section{Dietary and Dietetic ${ }^{\dagger}$}

\author{
Alfredo Pinzón-Junca • Bogotá, D.C. (Colombia)
}

DOI: https://doi.org/10.36104/amc.2020.1979

En ocasiones se emplean los términos dietético y dietario indistintamente para denominar elementos referentes a la alimentación. No obstante, el primero es el único adecuado en ese contexto. Aunque las dos palabras son similares, poseen significados diferentes:

Dietario: (Del latín bajo dieta, traducción del alemán Tag 'día’):

1. m. Libro en que se anotan los ingresos y gastos diarios de una casa.

2. m. Diario personal.

3. m. Libro en que los cronistas de Aragón escribían los sucesos más notables.

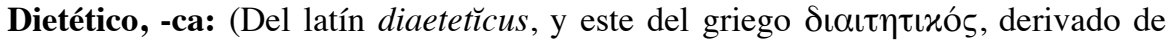
diaeta 'régimen de vida'):

1. adj. De la dieta o relacionado con ella [inglés: dietary].

2. adj. De la dietética o relacionado con ella [inglés: dietetic].

3. s.f. Disciplina científica que trata de los alimentos más adecuados para cada persona según sus características, con el fin de conseguir una alimentación adecuada o favorecer el tratamiento médico [inglés: nutrition, dietetics].

Quizás la equivocada traducción del inglés ha llevado al uso de expresiones inapropiadas en el idioma español, como «suplemento dietario» o «fibra dietaria», siendo sus formas correctas: suplemento dietético y fibra dietética.

\section{Fuentes}

- Diccionario de la Real Academia Española de la Lengua, disponible en: www.rae.es

- Real Academia Nacional de Medicina. Diccionario de Términos Médicos. Editorial Médica Panamericana. 2012

- Salas-Salvadó. Nutrición y Dietética Clínica. Cuarta Edición. Elsevier. 2019

$\uparrow$ Tema propuesto por el doctor Andrés Donado

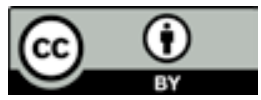

* Envíe sus inquietudes, sugerencias o comentarios a: contacto@actamedicacolombiana.com - alfpin@hotmail.com Dr. Alfredo Pinzón-Junca: Especialista en Medicina Interna y Psicoanálisis. Hospital Universitario de La Samaritana y Hospital Simón Bolívar. Coordinador del Consejo de Acreditación y Recertificación de la ACMI ${ }^{\circledR}$. Bogotá, D.C. (Colombia).

E-mail: alfpin@hotmail.com

Recibido: 2/VIII/2020 Aceptado: 3/VIII/2020 